\title{
FAZER ARTÍSTICO E "CRÍTICA" DA ARTE NUM EPISÓDIO MÍTICO (X 243- 297) DAS METAMORFOSES OVIDIANAS
}

\author{
Matheus Trevizam
}

\section{Introdução}

Nos últimos anos, tem-se com freqüência ressaltado a importância de Ovídio, prolífico autor romano, como poeta a refletir sobre vários processos atinentes à criação artística. ${ }^{1}$ Enquanto autor culto e consciente das regras de seu fazer, ele não hesita em trazer à tona, de maneiras muitas vezes sutis, os bastidores ou as implicações da obra do artista no mundo, amiúde nos oferecendo boas chances de divisarmos passagens metapoéticas.

Ainda, destacando-se por seu talento em evocar verbalmente vivas imagens e nutrindo-se em abundância do rico potencial pictórico associável à mitologia grega, pôde extravasar a própria sensibilidade com a feitura de "quadros" afins a formas representativas distintas. ${ }^{2}$ Com isso, reforçamos justamente as afinidades da poesia ovidiana com o domínio das artes plásticas no mundo antigo (pintura, escultura, tapeçaria...), ${ }^{3}$ podendo-se dizê-lo, à sua maneira, bom "pintor" ou, como se quiser, "entalhador" com palavras.

Embora, para os propósitos que nos dizem respeito aqui, não venhamos ocupar-nos exaustivamente dessa face mais "plástica" da arte de

\footnotetext{
${ }^{1}$ Especificamente, sobre a existência de passagens das Metamorfoses comprometidas com a indicação das "intenções" de Ovídio quanto ao modo de leitura desse texto, cf. palavras seguintes de Karl Galinsky, em tradução de Maria Ennis: No hay duda de que Ovídio perfila, sugiere, y da pistas acerca de la naturaleza de su esfuerzo poético y acerca del poeta (Galinsky, Karl. La poetologia de Ovídio en Las Metamorfosis. Trad. española de Maria Ennis, UNLP.

In. www.utexas.edu/depts/classics/faculty/Galinsky/poetologia.html. p. 1).

2 Parece curioso que, ainda no século XVII d.C., Diego Velázquez, mestre absoluto da pintura barroca em Espanha, ainda tivesse em Ovídio e, especificamente, nos panoramas descritivos das Metamorfoses, um importante referencial pictórico. Assim, entre seus pertences se encontraram exemplares das obras do poeta e várias das cenas míticas presentes em seus quadros (Las hilanderas, Las meninas) nos remetem diretamente ao universo imagético ovidiano; duas telas dependuradas na penumbra perto do teto em Las meninas, por exemplo, foram identificadas pelos estudiosos como oriundas de descrições do autor (cf. Wolf, Norbert. Velázquez: Trad. de Maria Eugénia Ribeiro da Fonseca. Köln: Benedikt Taschen Verlag, 2000, p. 69, 81).

${ }^{3}$ Em Metamorfoses VI 70-128, por exemplo, tem-se longas descrições das belas tapeçarias tecidas por Aracne e Atena em acirrada disputa pessoal (cf. Ovide. Les Métamorphoses. Texte établi et traduit par G. Lafaye. Paris: Les Belles Lettres, 1955. Tome II).
} 
Ovídio, interessa-nos estabelecer nexos entre ela e o aspecto supracitado da "reflexividade" do poeta. Pois, no episódio das Metamorfoses em pauta (X 243-297), parecem-nos conjugar-se o interesse ovidiano pelo enfoque imagético-crítico de um objeto artístico e, segundo sinalizado por Holzberg, ${ }^{4}$ a abertura para que se comente a elegia erótica romana por intermédio dele.

Isso posto, passaremos adiante a descrever tal imbricamento, de forma a favorecer-lhe a compreensão nos moldes de algo complexamente urdido para determinar alguns sentidos profundos do relato do mito de Pigmalião.

\section{O mito de Pigmalião, o fazer plástico do artista e suas conseqüências sobre a sensibilidade do "público"}

Os eventos evocados por Ovídio na passagem comentada são, quanto à estrutura narrativa, muito simples. Trata-se, como será talvez conhecido dos leitores do poeta, de apresentar um pequeno (mas importante) episódio da vida de um artista.

Assim, Pigmalião, escultor talentoso, evitava em rígido celibato a companhia de todas as mulheres por considerá-las viciosas; mas, insciente dos estranhos desdobramentos que isso teria, entalhou em marfim a figura impecavelmente acabada de uma virgem por quem veio, então, apaixonarse. ${ }^{5}$

Como é comum em se tratando dos amantes, cada mínimo detalhe do corpo amado (pois que, até esse momento, não tendo ainda ganhado alento, seria impossível à estátua apresentar traços de espírito) o embevecia e, fascinado, cumulava-o de presentes. Ei-lo, assim, a tocar-lhe a "pele", a beijar-lhe a face, a enlaçá-la, a acariciá-la, a dar-lhe quinquilharias (conchas, seixos polidos...), pássaros, flores, âmbar, anéis de pedras preciosas, longos colares, pérolas e correntes; e a vesti-la, a despi-la, a pô-la sobre tapetes de púrpura, a deitá-la consigo no leito sobre travesseiros de plumas... ${ }^{6}$

Nesse estágio do enlace, celebrava-se justamente na pátria de Pigmalião (a história se passa em Chipre, terra mais que todas cara a Vênus)

\footnotetext{
${ }^{4}$ Cf. Holzberg, Niklas. Ovid: the poet and his work. Translated from the German by G. M. Goshgarian. Ithaca/ London: Cornell University Press, 2002, p. 136-137).

${ }^{5}$ Cf. Metamorfoses X 243-253.

${ }^{6}$ Cf. Metamorfoses X 254-269.
} 
o dia votado à deusa do amor, e o apaixonado, aproveitando o momento para rogar uma graça, pediu-lhe que tivesse uma esposa parecida com a mulher de marfim a "aguardá-lo" inerte. Vênus, conhecedora do coração dos homens, porém, sabia que ele na verdade não esperava ter uma esposa como aquela, mas, propriamente, aquela como esposa; desse modo, satisfeita com o tempo geral de festa na ilha, bem como com a pietas desse sacrificante particular, ela decide por si conceder-lhe o favor que não ousara exprimir. ${ }^{7}$

De volta à casa, Pigmalião tenta mais uma vez tocar sua criatura, desta vez com sucesso: ocorre que, enfim favorecido por Vênus, vê a dureza ebúrnea ceder-lhe ao tato com maciez de membros humanos e beija, agora, lábios femininos. Não se deve omitir que a deusa responsável por essa metamorfose vem em pessoa assistir ao primeiro amplexo do casal, de que acabaria nascendo uma filha chamada Paphos. ${ }^{8}$

Ora, conforme as palavras ditas na introdução, notamos que esse trecho se identifica com mais uma das passagens de Ovídio em que o autor, embora modestamente, relaciona a poesia e as artes visuais. Aludimos não só ao fato de que se narre uma fábula envolvendo um escultor (e sua obra), mas ao elemento mais difundido do transparecer da habilidade imagética ovidiana; pois, não há que se esquecer, apontou-se ali certa face do mito de Pigmalião, tal qual tratado nesses versos, em seus vínculos com a usual feitura de quadros sensoriais pela palheta do poeta.

Assim, da mesma forma que Pigmalião, para "recortar" a escultura da massa amorfa da inexistência, recorrera aos meios da arte que distinguia seu ofício dos demais (usando, além do marfim como matéria-prima, provavelmente martelo e cinzel, por exemplo), Ovídio representa-a com palavras, sem que, por tal motivo, não nos faça também "vê-la" ou "tateála" com o espírito.

O ilusionismo artístico, pois, explica que a "divisemos" branca (da cor do marfim com que é feita), ${ }^{9}$ com as formas valorizadas pela arte clássica na mulher (havendo, é provável, a presença do arredondamento e da harmonia no corpo ${ }^{10} \mathrm{e}$, segundo uma tendência por vezes observada no adorno de estátuas antigas, sobretudo sacras, passível de vestir-se e ser

\footnotetext{
${ }^{7}$ Cf. Metamorfoses X 270-279.

${ }^{8}$ Cf. Metamorfoses 280-297.

${ }^{9}$ Cf. Metamorfoses X 247-248.

${ }^{10}$ Cf. Metamorfoses X 248-250.
} 
recoberta por adereços como brincos e colares preciosos; ${ }^{11}$ além disso, a própria natureza do marfim remete à característica tátil da maciez.

A título de comentário breve sobre os efeitos de ambos os modos de representar (o do escultor e o do poeta), lembremos, sempre tomando como ponto de partida um hipotético ideal de corpo feminino, ${ }^{12}$ a face mais imediata da arte de Pigmalião. Pois, bem o sabemos, a imagem da virgem depreensível dos versos de Ovídio corresponderia necessariamente a uma representação de algo que, em si, já manifestava caráter representativo. Ademais, do ponto de vista da efetiva existência de corpos femininos a se aproximarem mais ou menos desse ideal como atualizações relativas no mundo onde vivemos (o que viabilizara, por sinal, que o escultor moderasse eufemisticamente o tom das súplicas diante de Vênus!), o simulacro esculpido corresponde em parte às próprias características naturais do objeto.

Tem-se aqui, desse modo, além do maior afastamento do grau representativo ovidiano diante da verdadeira "realidade" (e, assim, de um mais "grave" ilusionismo), que o potencial envolvimento do criador com a criatura, no caso de Pigmalião, assume um caráter intrinsecamente físico, na acepção erótica da palavra. Isso nos permite ainda desdobrar a análise no sentido da observância de quem seria o "alvo" dos objetos e do fazer artístico em cada um dos ilusionismos.

Pois, em se tratando de dois simulacros invariavelmente destacados pelo traço da beleza (de outro modo, como explicar a súbita paixão do escultor?), há que se colocar a questão de como essa qualidade seria apreciada por receptores específicos em um e outro caso. Assim, no contexto interno do relato ovidiano, ter-se-ia Pigmalião, no momento posterior ao término da escultura, como o único apreciador do fruto da própria habilidade artística; por outro lado, o tom de nossos comentários até o presente momento deverá ter bastado para fazer ver o impacto da

${ }^{11}$ Cf. Metamorfoses X 263-265.

12 Partindo do princípio de que Pigmalião ninguém retratou ao criar sua estátua, remetemo-nos aqui à idéia platônica da representação artística, mesmo que diretamente calcada sobre um modelo físico, como cópia de segundo grau quanto à Idéia plena dos seres [cf. NATRIELLI, Adriana. A crítica do discurso poético na República de Platão. In: Martins, R. A.; Martins, L. A. C. P.; Silva, C.C.; Ferreira, J. M. H. (org.). Filosofia e história da ciência no Cone Sul: 3º. encontro. Campinas: AFHIC, 2004 , p. 10: Há uma cama que é a cama natural ou a Idéia de cama, única e essencial, da qual deus é o criador; uma segunda, a cama particular feita pelo artesão a partir da Idéia de cama anterior; e, por fim, a cama do pintor que imitou não a Idéia de cama, mas a cama particular tal como ela aparece. - Rep. 596e]. 
obra sobre esse espectador, intenso o bastante para que ele, esquecendo-se do óbvio, passasse mesmo a querer o improvável.

O mesmo não se dá quando "observamos" a amada de Pigmalião pelo viés da arte de Ovídio. Pois, bem se nota, o público alvo da pulcherrima uirgo seríamos nós próprios nessas circunstâncias... O mecanismo a explicar essa importante modificação identifica-se apenas com o fato de que, ao "ocultar" a imagem ${ }^{13}$ e desejá-la, como bom amante, egoisticamente e apenas para si, Pigmalião privara outros do privilégio de conhecer sua beldade, enquanto Ovídio, divulgando tal história aos leitores romanos (ou posteriores), estendera a mais pessoas as chances de "divisar-lhe" o perfil.

$\mathrm{E}$, fundamentalmente, não seria o caso de nos apaixonarmos por essa imagem feminina, primeiramente por não compartilharmos em igual medida do vivo senso imaginativo de Pigmalião e, também, por não podermos sequer enxergá-la, como dissemos, com a mesma imediatez dele. Pois o "filtro" das palavras, embora descritivas e aqui imbuídas, parece-nos, de potencial para despertar-nos ao menos a curiosidade, basta para furtarnos a esse risco. ${ }^{14}$

\section{A descrição ovidiana da uirgo amata e sua instrumentalização para a "crítica" da arte e da elegia erótica romana}

Tendo já assinalado fatores comuns (ou de divergência) entre o entalhe da mulher por Pigmalião e o "mesmo" processo nas mãos de Ovídio, ultrapassemos agora tal etapa para fazê-la ponto de partida de nossas reflexões sobre a face "crítica" do poeta diante da arte, amplamente compreendida.

Parece-nos possível, com efeito, considerar certas descrições ovidianas a respeito da imagem em questão como algo afim à apreciação "crítica" do objeto focado. Assim, em X 247-252, lê-se:

Interea niueum mira feliciter arte

Sculpsit ebur formamque dedit, qua femina nasci

Nulla potest; operisque sui concepit amorem.

Virginis est uerae facies, quam uiuere credas,

250

\footnotetext{
${ }^{13}$ Cf. Metamorfoses X 280.

${ }^{14}$ Cf. Horácio. Arte poética. Tradução de Jaime Bruna. São Paulo: Cultrix, 1997, p. 60: As ações ou se representam em cena ou se narram. Quando recebidas pelos ouvidos, causam emoção mais fraca do que quando, apresentadas à fidelidade dos olbos, o espectador mesmo as testemunha.
} 
Et, si non obstet reuerentia, uelle moueri;

Ars adeo latet arte sua. ${ }^{15}$

Ora, descrevendo o corpo e, simultaneamente, recriando-o mais uma vez, como não perceber que Ovídio "forja" um instrumento para que ele lhe sirva de ponto de apoio a comentários sobre a arte da escultura ou da elegia? Assim, um olhar mais detido para as expressões grifadas acima permitir-nos-ia considerá-las como apontamentos "críticos" sumários, destinados a esclarecer a natureza dos processos artísticos em pauta.

De início, pois, no verso 247, a arte de Pigmalião (contraponto do poeta elegíaco no âmbito do fazer plástico) e, por extensão, a própria figura da amada, é considerada mira por Ovídio. Parece-nos viável interpretar o adjetivo não só nos termos do reconhecimento pelo "crítico" da excelência da técnica e do objeto representado pelas mãos de criadores do calibre de Pigmalião (ou dele próprio, ocupado em sua juventude com a escrita das elegias eróticas dos Amores), mas também como algo vinculado a faces alheias ao banal; pois, na verdade, ambos os tipos de puellae, por suas características diferenciadas daquelas da média das mulheres romanas, apresentam-se-nos aos olhos com portes muito específicos. ${ }^{16}$

E, na continuidade desse ponto, o que se tem em seguida, logo em 248-249, delineia ainda as fronteiras entre a vida e o "fingimento". No caso particular de Pigmalião e sua criatura, o próprio excesso de beleza da estátua, provavelmente materializado em graça e incomum harmonia anatômica, contribui, como dissemos, para a montagem de uma figura sui generis, a princípio sem grandes chances reais de repetir-se no quotidiano. ${ }^{17}$ E, para suas "irmãs" inseridas no universo da elegia erótica romana (uma Cíntia, uma Nêmesis, uma Délia, uma Corina...), o mesmo se poderia propor na medida em que, justamente intensas a ponto de ocuparem todo o espaço de vida dos poetas-amantes que as cantam, além de destacadas por um conjunto de traços afins à beleza, elegância, refinamento, inteligência e

\footnotetext{
15 Nisso, com maravilhosa arte felizmente o alvo/ marfim esculpin e modelou, como mulher algumal pode nascer; $e$ apaixonou-se por sua obra./ Tem o rosto mesmo de uma virgem - julgar-se-ia viver -/ e, não a impedindo o acanbamento, querer andar;/ a tal ponto se oculta a arte em sua arte (minha tradução).

${ }^{16}$ Sobre a mulher elegíaca, consideremos os versos iniciais do primeiro carmen properciano na tradução de Zelia de A. Cardoso: Cintia, com seu olhar, foi a primeira que me enfeitiçou/ (infeliz, não tocado anteriormente por nenbuma forma de paixão)./ O Amor, então, abateu-me o brilho da firme altivez,/ dominou minha cabeça, calcando os pés sobre ela, / e ao mesmo tempo me ensinou, falso que é,/ a ter ódio das moças honestas e a viver sem pensar [cf. Nery, Maria Luiza; Novak, Maria da Glória (org.). Poesia lírica latina. São Paulo: Martins Fontes, 1992, p. 145].

${ }^{17}$ Cf. supra nota 14.
} 
sensualidade, elevam-se ao topo do possível para a mulher no quesito dos atributos de sedução. ${ }^{18}$

Em X 250, porém, nuança-se essa posição dizendo que o rigor de feitura da imagem é tamanho que poderia levar a crer tratar-se de mulheres reais. Dessa maneira, embora os limites entre a arte e o "fingir" artístico tenham sido bem postos pelo "crítico", a possibilidade de haver confusões não é de todo rechaçada, como o comprova a súbita paixão de Pigmalião pela mulher de marfim e alguns entendimentos de leitores de poesia (incluindo a elegia) em Roma antiga ${ }^{19}$ e em nossos dias.

Por fim, o verso 252 expõe um princípio caro à arte clássica em geral: ${ }^{20}$ trata-se, como notamos, de considerar bom artista aquele capaz de "camuflar" os sinais de feitura de seu artefato poético ou de outra natureza, sem, o que nos parece de todo impossível, chegar a apagá-los. Com isso, aproxima-se a obra de um parâmetro de qualidade próximo do impecável e se favorece, ainda, apreender sutilmente que deparamos um construto, vinculado sem sombra de dúvida a um fazer calculado para produzir efeitos sobre o público.

Como balanço geral a respeito dos comentários "críticos" de Ovídio sobre a escultura da amada e, segundo Holzberg, o universo poético da elegia erótica romana (devido à constatação de o artista "retratado" ser, na mesma hora, amante e artífice da criatura, e de seu sofrimento amoroso por ela dever-se a que fosse uma dura puella), ${ }^{21}$ reforçamos o tom positivo das apreciações e os avisos contra os falaciosos meandros da arte bem realizada. No primeiro caso, dessa maneira, tratar-se-ia de enaltecer pela via da boa apresentação imagética das puellae (ocupamo-nos aqui de um trecho, tal qual citado, identificável com propósitos descritivos) não apenas a qualidade de artefatos em si compreendidos, mas também o trabalho dos artistas envolvidos com seu cuidadoso "entalhe".

No segundo, como vimos, em que pese à inevitável dúvida a respeito do nível de "realidade" passível de associar-se às amadas (elegíacas

\footnotetext{
${ }^{18}$ Cf. supra nota 15.

${ }^{19}$ Cf. poema XVI 5-13 de Catulo, na tradução de J. A. Oliva Neto (Catulo. O livro de Catulo. Tradução, introdução e notas de J. A. Oliva Neto. São Paulo: Edusp, 1996, p. 80): A um poeta pio convém ser casto/ ele mesmo, aos seus versos não há lei./ Estes só têm sabor e graça quando/ são delicados, sem nenhum pudor; $e$ quando incitam o que excite não/ digo os meninos, mas esses peludos/ que jogo de cintura já não têm./ E vós, que muitos beijos (aos milhares)/ já lestes, me julgais não ser viril?

${ }^{20}$ Cf. Ovidio. L'arte di amare. A cura di E. Pianezzola. Milano: Lorenzo Valla/ Mondadori, s.d., II 313: Si latet ars, prodest ("caso a arte se esconda, tem efeito" - minha tradução).

21 Cf. supra nota 4.
} 
ou ebúrnea), nunca paira o engano sobre o realismo manifesto, ademais, entendido por Ovídio como critério válido para a boa compreensão do que seria um bom objeto artístico. Acreditamos, assim, que a chance mesma da boa avaliação de ambos os tipos de simulacro feminino sob o olhar ovidiano está subordinada a esse fator de primoroso término, quesito indispensável para situar a arte nos limiares da verdade e livrá-la do esquecimento.

No esteio, então, do que vimos propondo desde o início, espera-se ter oferecido subsídios para que se compreenda o papel da representação da figura da amada em sua dupla função, considerando a parte ovidiana do processo imitativo. Com isso, aludimos ao emprego desse "corpo" tecido nos versos do autor simultaneamente como modo acessível ao artista para o esboço do retrato de tão notável criatura e como forma de comentar a arte em duas frentes distintas, cabendo à "crítica" da escultura, julgamos, um papel mais imediato no quadro total, enquanto a metapoesia sustentar-se-ia sobre ela.

Pois, de fato, se houvermos a rigor de considerar que Ovídio fala sobre alguma coisa, posicionando-se a seu respeito, isso seria o artefato criado pelas mãos de Pigmalião. A idéia de Holzberg, nesse sentido, embora nos pareça de todo cabível dado o supracitado destaque da metapoesia no panorama da obra do autor latino, encaixar-se-ia em nossas reflexões num plano interpretativo mais profundo, a demandar maior esforço para que se pudesse fazer presente e acatada pelo espírito.

Por fim, a título de encerramento dessas breves reflexões, considera-se de utilidade fazer atentar para a eficácia do simulacro ovidiano nos papéis a que se prestou no contexto visto. Embora menos "intenso", é provável, ${ }^{22}$ do que a estátua de Pigmalião, embora mais mimético (e não "real") em escala ilusória, trata-se de um artefato discursivo, como explicamos, passível de valer por si e ao apontar criticamente para outras realidades.

O mesmo seria possível para uma estátua de marfim, ainda que impecavelmente acabada? Parece-nos, exceto se a arte de Pigmalião fosse pretender-se conceitual avant la lettre, que não...

\footnotetext{
${ }^{22}$ Cf. supra nota 14.
} 


\section{Bibliografia}

CATULO. O livro de Catulo. Tradução, introdução e notas de J. A. Oliva Neto. São Paulo: Edusp, 1996.

GALINSKY, Karl. La poetologia de Ovídio en Las Metamorfosis. Trad. española de Maria Ennis, UNLP. In. www.utexas.edu/depts/classics/faculty/Galinsky/poetologia.html.

HOLZBERG, Niklas. Ovid: the poet and his work. Translated from the German by G. M. Goshgarian. Ithaca/ London: Cornell University Press, 2002.

HORÁCIO. Arte poética. Tradução de Jaime Bruna. São Paulo: Cultrix, 1997.

NATRIELLI, Adriana. A crítica do discurso poético na República de Platão. In: Martins, R. A.; Martins, L. A. C. P.; Silva, C.C.; Ferreira, J. M. H. (org.). Filosofia e história da ciência no Cone Sul: $3^{\circ}$. encontro. Campinas: AFHIC, 2004.

NERY, Maria Luiza; NOVAK, Maria da Gloria (org.). Poesia lírica latina. São Paulo: Martins Fontes, 1992.

OVIDE. Les Métamorphoses. Texte établi et traduit par G. Lafaye. Paris: Les Belles Lettres, 1955. Tome II.

OVIDIO. L'arte di amare. A cura di E. Pianezzola. Milano: Lorenzo Valla/ Mondadori, s.d.

WOLF, Norbert. Velárquez: Trad. de Maria Eugénia Ribeiro da Fonseca. Köln: Benedikt Taschen Verlag, 2000. 